\title{
VDR mRNA overexpression is associated with worse prognostic factors in papillary thyroid carcinoma
}

\author{
June Young Choi ${ }^{1, *}$, Jin Wook $\mathrm{Yi}^{2, *}$, Jun Hyup Lee ${ }^{2}$, Ra-Yeong Song ${ }^{2}$, \\ Hyeongwon Yu1, Hyungju Kwon², Young Jun Chai ${ }^{3}$, Su-jin Kim² and Kyu Eun Lee ${ }^{2}$ \\ 'Department of Surgery, Seoul National University Bundang Hospital, Seongnam-si, Korea \\ 2Department of Surgery, Seoul National University Hospital and College of Medicine, Seoul, Korea \\ ${ }^{3}$ Department of Surgery, Seoul National University Boramae Hospital, Seoul, Korea \\ *(J Y Choi and J W Yi contributed equally as a co-first authors)
}

Correspondence should be addressed to K E Lee Email

kyueunlee@snu.ac.kr

\begin{abstract}
The purpose of this study was to assess the relationship between vitamin $D$ receptor gene (VDR) expression and prognostic factors in papillary thyroid cancer (PTC). mRNA sequencing and somatic mutation data from The Cancer Genome Atlas (TCGA) were analyzed. VDR mRNA expression was compared to clinicopathologic variables by linear regression. Tree-based classification was applied to find cutoff and patients were split into low and high VDR group. Logistic regression, Kaplan-Meier analysis, differentially expressed gene (DEG) test and pathway analysis were performed to assess the differences between two VDR groups. VDR mRNA expression was elevated in PTC than that in normal thyroid tissue. VDR expressions were high in classic and tall-cell variant PTC and lateral neck node metastasis was present. High VDR group was also associated with classic and tall cell subtype, AJCC stage IV and lower recurrence-free survival. DEG test reveals that 545 genes were upregulated in high VDR group. Thyroid cancer-related pathways were enriched in high VDR group in pathway analyses. VDR mRNA overexpression was correlated with worse prognostic factors such as subtypes of papillary thyroid carcinoma that are known to be worse prognosis, lateral neck node metastasis, advanced stage and recurrence-free survival.
\end{abstract}

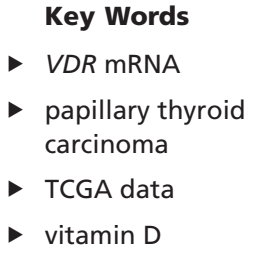

Endocrine Connections (2017) 6, 172-178

\section{Introduction}

Thyroid carcinoma is the most common endocrine malignancy worldwide, the incidence of which is increasing. The most common subtype of thyroid carcinoma is papillary carcinoma (PTC), accounting for 80-90\% of all cases (1). Although this type of cancer has an excellent prognosis, the prognosis significantly worsens when the tumor grows and metastasizes (2). For this reason, it is important to understand the characteristics of the tumor at the early stage.

Several epidemiological reports show that higher levels of vitamin D3 are associated with a lower risk of developing cancer (3). The active form of vitamin D3, 1,25-dihydroxyvitamin D3 (1,25D) exerts antitumor activity by binding to the vitamin $\mathrm{D}$ receptor $(V D R)$. The antitumor activities of $1,25 \mathrm{D}$ include the inhibition of cancer cell proliferation and angiogenesis, promotion of cell differentiation and apoptosis $(4,5,6,7,8)$.

The $V D R$ is a receptor expressed by epithelial cells in both normal and malignant thyroid glands. Human VDR gene is located on chromosome 12q13.1 (9). In cancer cells, $V D R$ expression is a response to 1,25-dihydroxyvitamin D3 $(1,25 \mathrm{D})$ by decreasing proliferative activity in vitro. Izkhakov and coworkers reported that expression of $V D R$ mRNA in malignant thyroid tissues is higher than that http://www.endocrineconnections.org DOI: 10.1530/EC-17-0001 (c) 2017 The authors Published by Bioscientifica Ltd

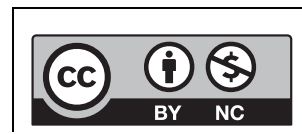

This work is licensed under a Creative Commons Attribution-NonCommercial 4.0 International License. 
in normal thyroid (2). They also reported correlations between VDR and other genes such as ECM1 (extracellular matrix protein-1) and TMPRSS4 (type II transmembrane serine protease-4), which are associated with tumor progression. Positive correlation was also observed between VDR and ECM1, as well as between $V D R$ and TMPRSS4 (2).

Our study was designed to evaluate the correlation between the VDR mRNA expression and prognostic factors of PTC using 'The Cancer Genome Atlas' (TCGA) data. TCGA kindly provides multiplatform genomics data such as sequence and read count data from next-generation sequencing, copy-number analysis, methylomics and proteomics data (10). Genomic data were also combined with patient-matched clinical data to correlate the molecular findings with clinical characteristics.

\section{Materials and methods}

\section{Data preparation}

We downloaded TCGA thyroid cancer data, including clinical information, somatic mutations and gene expression data derived from RNA sequencing. Pathologic data were re-evaluated using scanned images of the paper-written pathologic documents provided by TCGAassociated hospitals. PTC subtype classification and MACIS scores were referenced from the 2014 TCGA thyroid cancer paper's Supplemental Tables (10). The total number of TCGA samples comprised 59 normal tissues and 501 cancer tissues. Total 499 patient samples were assessed after joining the clinical data without missing attributes.

Somatic mutations were provided by two different mutation calling files from the Illumina DNA-sequencing machine. Sequencing experiments were performed by the Baylor College of Medicine, the Broad Institute at MIT and Harvard Genome Sequencing Center. Mutation status of BRAF, RAS (NRAS, HRAS and KRAS) and VDR genes was identified from somatic mutation calling files: identical results in two different calling files were considered as a meaningful mutation.

TCGA gene expression data from RNA sequencing were provided with level 3 RSEM (RNA-Seq by expectationmaximization) counts after upper quartile normalization to maintain the standardization of different platforms or housekeeping genes (https://wiki.nci.nih.gov/). RNA sequencing was performed by the University of North Carolina using an Illumina HiSeq RNA Sequencing machine. We analyzed VDR gene expression according to tissue type (normal vs cancer) and clinical information. Next, all 20,531 genes were used to assess gene ontology and pathway analysis.

\section{Statistical analysis}

Paired $t$-test was used to assess the differences in gene expression between 59 paired donor-matched normal and cancer samples, whereas unpaired $t$-test was used to assess the global differences between the 59 normal tissues and 499 cancer tissues. Association between clinical variables and $V D R$ gene expression was measured by univariable and multivariable linear regression analysis. To predict cancer recurrence based on VDR expression, continuous $V D R$ expressions was converted into two binary groups (low $V D R$ and high $V D R$ group) using tree-based classification analysis with a maximized area under the ROC (receiveroperating characteristic) curve. Binary VDR groups were used for univariable and multivariable logistic regression analyses to assess the relationship between VDR expression and clinicopathologic variables. Backward selection method was used in both linear and logistic regression for multiple model fitting. Kaplan-Meier estimator with logrank test was used for survival analysis.

Differentially expressed genes (DEG) and geneontology (GO) tests between two VDR groups were performed using 'EdgeR' package, which is one of the bioinformatics tools in Bioconductor (https://www.bioconductor.org/) (11). Pathway enrichment analysis was performed using The Database for Annotation, Visualization and Integrated Discovery (DAVID) $(12,13)$ and the Gene Set Enrichment
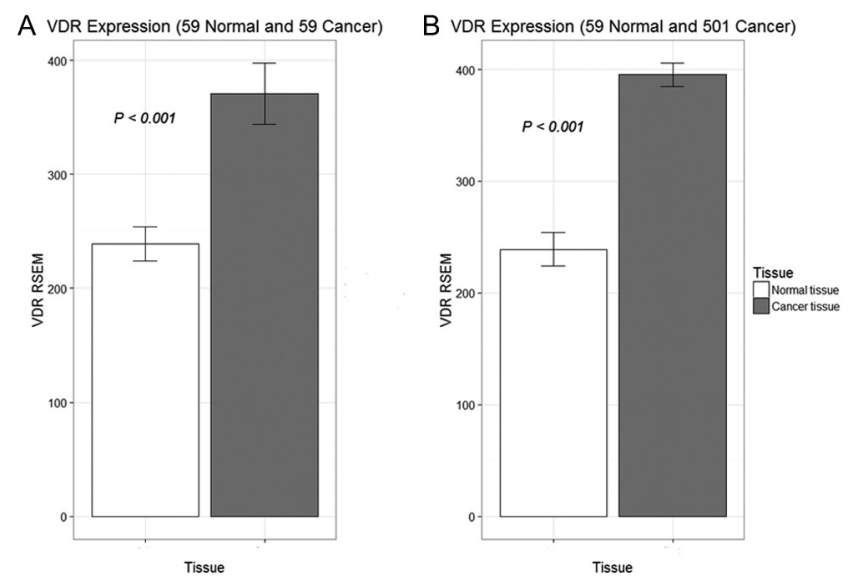

Figure 1

VDR mRNA expression counts in normal and papillary thyroid carcinoma tissue. (A) Fifty-nine paired normal and cancer tissues. (B) 59 normal vs 501 cancer tissues. 
Analysis (GSEA) program (14). False discovery rate (FDR) correction was used to adjust false-positive rate from multiple testing. All statistical analyses were performed using R 3.2.4. (R Core Team (2016). R: A language and environment for statistical computing. R Foundation for Statistical Computing, Vienna, Austria. URL https:// www.R-project.org/).

\section{Results}

No VDR gene single-nucleotide variants were observed in either of the two different mutation calling files. Figure 1 shows the difference in VDR mRNA expression between normal and PTC tissues. Both paired and unpaired tests revealed that $V D R$ expression was higher in cancer tissue than that in normal tissue (VDR expression in 55 normal tissues $=238.971 \pm 14.987$; in 55 paired cancer tissues $=307.567 \pm 26.808$; in 501 cancer tissues $=395.276 \pm 10.323$, mean \pm standard error of mean (s.E.M.)).

Correlations of VDR mRNA expression according to clinicopathologic variables are shown in Table $1 . V D R$ gene expression was higher with statistical significance in classic and tall-cell variant PTC (TCVPTC) than that in follicular variant PTC (FVPTC). VDR expression was also significantly upregulated in cases with T4 (tumor stage), N1b (lateral neck node metastasis), high MACIS group

Table 1 Association between VDR mRNA expression and clinicopathologic characteristics of 499 PTC patients by linear regression analysis.

\begin{tabular}{|c|c|c|}
\hline Variable & & Number \\
\hline \multirow[t]{2}{*}{ Age } & $<45$ & 228 \\
\hline & $\geq 45$ & 271 \\
\hline \multirow[t]{2}{*}{ Gender } & $\mathrm{M}$ & 134 \\
\hline & $\mathrm{F}$ & 365 \\
\hline \multirow[t]{4}{*}{ Subtype } & Classic PTC & 355 \\
\hline & FVPTC $^{\dagger}$ & 101 \\
\hline & TCVPTC $^{\ddagger}$ & 35 \\
\hline & Others & 8 \\
\hline \multirow[t]{2}{*}{ Size } & $\leq 2 \mathrm{~cm}$ & 200 \\
\hline & $>2 \mathrm{~cm}$ & 299 \\
\hline \multirow[t]{2}{*}{ Lymphovascular invasion } & No & 392 \\
\hline & Yes & 107 \\
\hline \multirow[t]{4}{*}{ T stage } & $\mathrm{T} 1$ & 144 \\
\hline & $\mathrm{T} 2$ & 154 \\
\hline & T3 & 184 \\
\hline & $\mathrm{T} 4$ & 17 \\
\hline \multirow[t]{3}{*}{ N stage } & NO & 278 \\
\hline & N1a & 120 \\
\hline & $\mathrm{N} 1 \mathrm{~b}$ & 101 \\
\hline \multirow[t]{2}{*}{ M stage } & MO & 490 \\
\hline & M1 & 9 \\
\hline \multirow[t]{3}{*}{ MACIS } & Low & 345 \\
\hline & Intermediate & 78 \\
\hline & High & 76 \\
\hline \multirow[t]{4}{*}{ Stage } & 1 & 289 \\
\hline & II & 44 \\
\hline & III & 98 \\
\hline & IV & 68 \\
\hline \multirow[t]{3}{*}{$B R A F$ mutation } & No & 258 \\
\hline & V600E & 236 \\
\hline & Others & 5 \\
\hline \multirow[t]{2}{*}{ RAS mutation } & No & 446 \\
\hline & Yes & 53 \\
\hline \multirow[t]{2}{*}{ Recurrence } & No & 459 \\
\hline & Yes & 40 \\
\hline \multirow[t]{2}{*}{ Survival } & Alive & 485 \\
\hline & Dead & 14 \\
\hline
\end{tabular}

\begin{tabular}{c} 
Mean \pm s.E.M. \\
\hline $390.989 \pm 14.257$ \\
$399.888 \pm 14.838$ \\
$372.818 \pm 17.539$ \\
$404.267 \pm 12.590$ \\
$408.001 \pm 12.670$ \\
$318.546 \pm 19.165$ \\
$494.194 \pm 32.023$ \\
$400.611 \pm 98.383$ \\
$399.179 \pm 15.865$ \\
$393.576 \pm 13.657$ \\
$393.643 \pm 11.827$ \\
$403.803 \pm 21.394$ \\
$377.999 \pm 17.633$ \\
$382.805 \pm 20.737$ \\
$411.481 \pm 16.151$ \\
$495.216 \pm 61.736$ \\
$363.768 \pm 12.188$ \\
$410.893 \pm 23.858$ \\
$466.142 \pm 24.895$ \\
$396.254 \pm 10.494$ \\
$372.300 \pm 58.740$ \\
$386.576 \pm 12.243$ \\
$383.270 \pm 24.077$ \\
$450.675 \pm 29.909$ \\
$379.548 \pm 12.535$ \\
$367.811 \pm 35.599$ \\
$410.995 \pm 26.292$ \\
$461.242 \pm 30.243$ \\
$378.672 \pm 15.039$ \\
$415.103 \pm 14.299$ \\
$370.710 \pm 82.387$ \\
$399.870 \pm 11.187$ \\
$361.755 \pm 25.071$ \\
$390.370 \pm 10.905$ \\
$458.378 \pm 30.682$ \\
$394.442 \pm 10.422$ \\
$443.627 \pm 78.110$ \\
\hline
\end{tabular}

\begin{tabular}{|c|c|}
\hline $\boldsymbol{P}$ value (univariate) & $\boldsymbol{P}$ value (multivariate) \\
\hline 0.669 & \\
\hline 0.179 & 0.058 \\
\hline
\end{tabular}

$\begin{array}{cc}\text { Reference } & \text { Reference } \\ <0.001 & 0.009 \\ 0.033 & 0.059 \\ 0.928 & 0.955 \\ 0.791 & \\ 0.688 & \end{array}$

${ }^{\dagger}$ Follicular variant PTC; ${ }^{\ddagger}$ tall cell variant PTC.

$\begin{array}{cc}\text { Reference } & \\ 0.858 & \\ 0.193 & \\ 0.048 & \\ \text { Reference } & \text { Reference } \\ 0.059 & 0.381 \\ <0.001 & 0.002 \\ 0.759 & \end{array}$

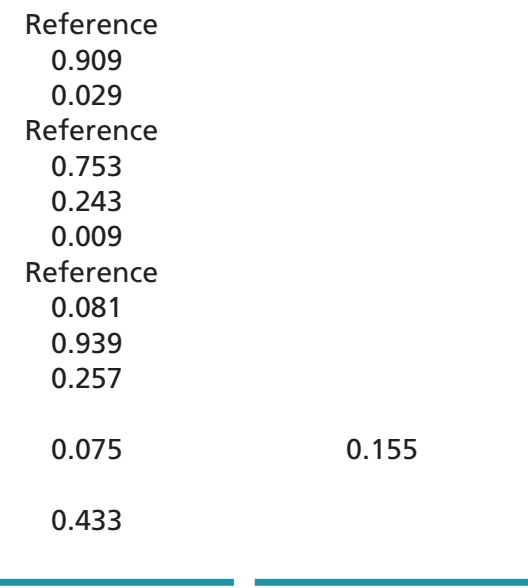

\begin{tabular}{|lr}
\hline http://www.endocrineconnections.org & ○ 2017 The authors \\
DOI: $10.1530 /$ EC-17-0001 & Published by Bioscientifica Ltd
\end{tabular}

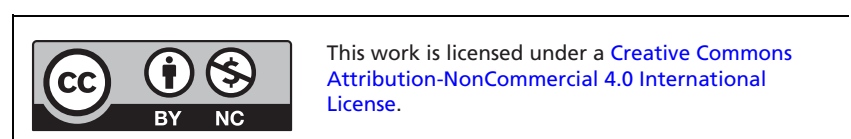


Table 2 Logistic regression analysis using binary VDR mRNA expression (cutoff value $=466.5 ; A U C=0.624$; low VDR group, $n=342$; high VDR group, $n=157$ ).

\begin{tabular}{|c|c|c|c|c|c|}
\hline \multirow[b]{2}{*}{ Variables } & & \multicolumn{2}{|c|}{ Univariate } & \multicolumn{2}{|c|}{ Multivariate } \\
\hline & & Odds ratio & $P$ value & Odds ratio & $P$ value \\
\hline Age $(<45)$ & $\geq 45$ & 1.108 & 0.597 & & \\
\hline Gender (M) & Female & 1.057 & 0.801 & & \\
\hline \multirow[t]{3}{*}{ Subtype (classic) } & FVPTC & 0.515 & 0.016 & 0.576 & 0.051 \\
\hline & TCVPTC & 2.783 & 0.004 & 2.540 & 0.013 \\
\hline & Others & 0.696 & 0.660 & 0.764 & 0.747 \\
\hline Size $(\leq 2 \mathrm{~cm})$ & $>2 \mathrm{~cm}$ & 0.923 & 0.683 & & \\
\hline Lymphovascular invasion (No) & Yes & 1.263 & 0.309 & & \\
\hline \multirow[t]{3}{*}{$\mathrm{T}$ stage $(\mathrm{T} 1)$} & $\mathrm{T} 2$ & 0.823 & 0.458 & & \\
\hline & T3 & 1.507 & 0.086 & & \\
\hline & T4 & 2.826 & 0.046 & & \\
\hline \multirow[t]{2}{*}{ N stage (N0) } & N1a & 1.431 & 0.128 & & \\
\hline & $\mathrm{N} 1 \mathrm{~b}$ & 1.962 & 0.006 & & \\
\hline M stage (M0) & M1 & 1.091 & 0.903 & & \\
\hline \multirow[t]{2}{*}{ MACIS (low) } & Intermediate & 1.156 & 0.592 & & \\
\hline & High & 1.782 & 0.027 & & \\
\hline \multirow[t]{3}{*}{ Stage (I) } & II & 0.649 & 0.275 & 0.807 & 0.596 \\
\hline & III & 1.341 & 0.239 & 1.080 & 0.772 \\
\hline & IV & 2.244 & 0.003 & 1.925 & 0.020 \\
\hline \multirow[t]{2}{*}{$B R A F$ mutation (No) } & V600E & 1.349 & 0.123 & & \\
\hline & Others & 1.689 & 0.570 & & \\
\hline RAS mutation (No) & Yes & 0.538 & 0.080 & & \\
\hline Recurrence (No) & Yes & 2.625 & 0.004 & 2.329 & 0.014 \\
\hline Survival (alive) & Dead & 1.217 & 0.729 & & \\
\hline
\end{tabular}

and AJCC stage IV. Gender, PTC subtype and N stage were only included in multiple linear regression model. The results also showed an association between $V D R$ expression with $B R A F^{\mathrm{V} 600 \mathrm{E}}$ mutation and recurrence, although the results did not reach statistical significance.

To predict recurrence using VDR gene expression, we divided continuous $V D R$ expression values into binary variables using the tree-based classification and ROC curve. Optimal VDR cutoff value obtained was 466.5, with

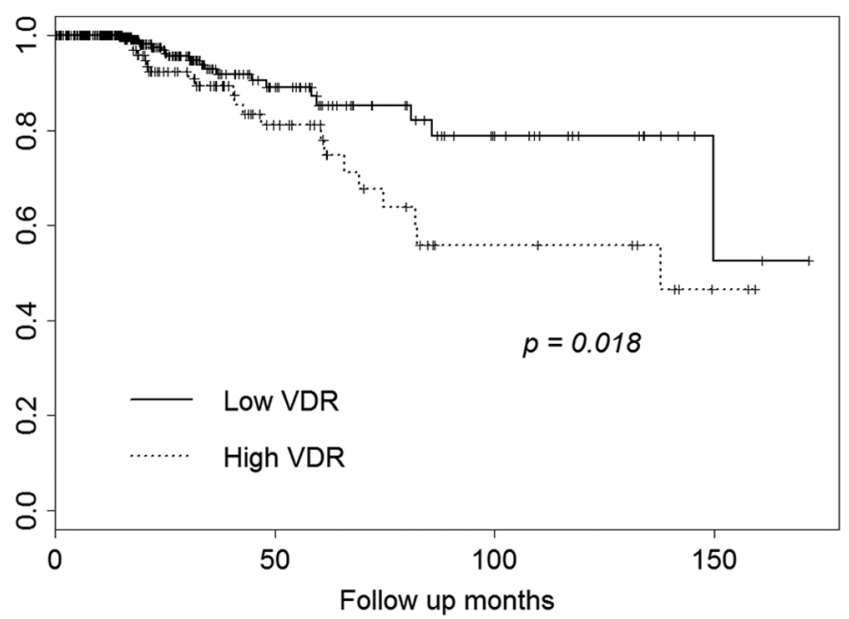

Figure 2

Recurrence-free survival in the low and high VDR expression groups.

http://www.endocrineconnections.org
$\begin{array}{lr}\text { DOI: } 10.1530 / \text { EC-17-0001 } 2017 \text { The authors } \\ \text { Published by Bioscientifica Ltd }\end{array}$

a maximal AUC of 0.624. Based on the cutoff, patients were divided into a low $V D R$ group and a high $V D R$ group. Low VDR group comprised 342 patients and high $V D R$ group comprised 157 patients. Table 2 shows the logistic regression results according to binary VDR group. Both the univariable and multivariable regression models revealed that high VDR group was associated with classic PTC and TCVPTC, advanced AJCC stage (stage IV) and recurrence.

Total 40 patients showed recurrence after surgery. 21 patients had locoregional recurrence including central and lateral neck nodes, whereas 15 patients had distant recurrence such as bone, lung, etc. There is no information for four patients. In high VDR group, 11 patients had locoregional and six patients had distant recurrence $(P$ value from Fisher's exact test $=0.002)$. Figure 2 illustrates recurrence-free survival difference for two VDR groups using the Kaplan-Meier estimator. The high VDR group showed worse recurrence-free survival than the low VDR group $(P$ value $=0.018$, follow-up duration: median 647 days, range 1-5150 days). There's no statistical significance in overall survival between the two VDR groups.

We performed DEG tests for the low and high VDR groups using EdgeR package. The differential gene expression pattern is shown in Fig. 3. DEG boundaries were defined as follows: average log CPM (counts per million)

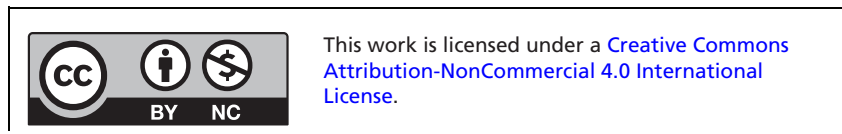




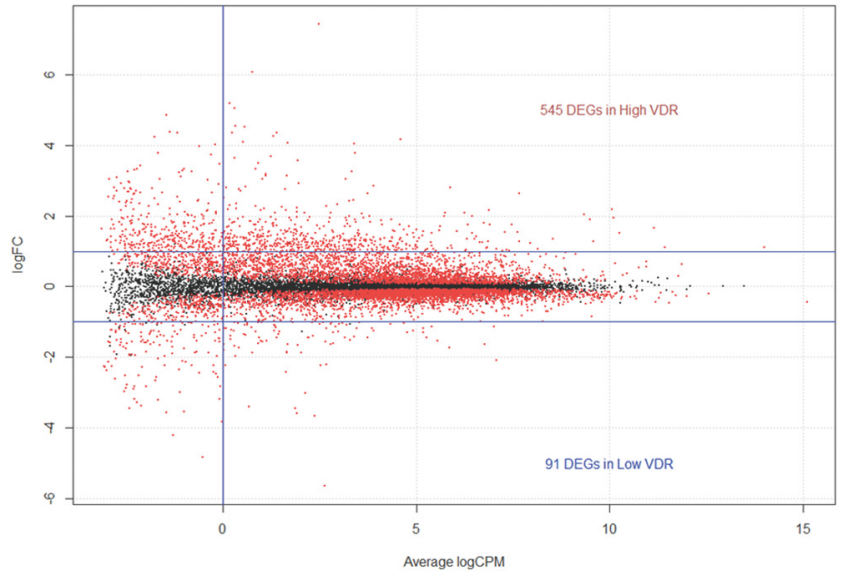

Figure 3

MA plot of genes differentially expressed in the low and high VDR expression groups. DEG cutoff consisted of average logCPM

(count per million) $>0$, | logFC (fold change) $\mid>1$ and FDR $q$-value $<0.01$.

$>0$ and $\mid \log$ FC (fold change) $\mid>1$, and FDR $q$-value $<0.01$ (indicated as vertical and horizontal lines in Fig. 3). A total of 545 genes were highly expressed in high VDR group, whereas 91 genes were highly expressed in low $V D R$ group. Table 3 lists the top 20 highly expressed DEGs in high $V D R$ group.

Supplementary Table 1 (see section on supplementary data given at the end of this article) shows the pathways that are significantly enriched by 545 upregulated DEGs in high VDR group, using DAVID. Cellular interaction, autoimmune thyroid disease, immune receptor-related signal pathways, cancer-related chemokine signaling

Table 3 Top 20 upregulated genes in the high VDR group.

\begin{tabular}{|c|c|c|c|c|c|}
\hline Gene ID & Gene symbol & $\log F C$ & $\log C P M$ & $P$ value & FDR \\
\hline 7421 & $V D R$ & 1.282 & 4.312 & 2.61E-149 & 4.39E-145 \\
\hline 165904 & $X I R P 1$ & 4.100 & 0.524 & 3.83E-93 & $3.22 \mathrm{E}-89$ \\
\hline 256076 & COL6A5 & 6.088 & 0.755 & $4.51 \mathrm{E}-92$ & $2.53 E-88$ \\
\hline 57016 & $A K R 1 B 10$ & 7.436 & 2.483 & $1.73 E-86$ & 7.27E-83 \\
\hline 1646 & $A K R 1 C 2$ & 4.052 & 3.393 & $1.47 \mathrm{E}-78$ & $4.95 E-75$ \\
\hline 2877 & GPX2 & 5.053 & 0.296 & $4.00 \mathrm{E}-77$ & $1.12 \mathrm{E}-73$ \\
\hline 146802 & SLC47A2 & 3.199 & 1.098 & $1.38 E-59$ & $3.32 E-56$ \\
\hline 8038 & ADAM12 & 2.429 & 3.250 & $3.35 E-56$ & $7.05 E-53$ \\
\hline 8111 & GPR68 & 1.868 & 2.199 & $4.08 E-53$ & $6.24 \mathrm{E}-50$ \\
\hline 729238 & SFTPA2 & & 4.587 & $9.36 \mathrm{E}-53$ & $1.31 \mathrm{E}-49$ \\
\hline 10468 & FST & 2.823 & 0.579 & $1.06 \mathrm{E}-51$ & 1.37E-48 \\
\hline 1281 & COL3A1 & 2.048 & 9.347 & $4.38 \mathrm{E}-50$ & 4.91E-47 \\
\hline 6947 & TCN1 & 4.253 & 1.294 & $9.78 \mathrm{E}-50$ & $1.03 E-46$ \\
\hline 1278 & COL1A2 & 1.894 & 9.490 & $2.00 \mathrm{E}-48$ & $1.87 E-45$ \\
\hline 1293 & COL6A3 & 1.761 & 7.459 & $3.02 E-48$ & 2.67E-45 \\
\hline 3909 & LAMA3 & 2.289 & 2.671 & $1.02 \mathrm{E}-47$ & $8.32 E-45$ \\
\hline 92747 & BPIFB1 & 4.529 & 0.566 & $1.04 \mathrm{E}-47$ & 8.32E-45 \\
\hline 10699 & CORIN & 1.836 & 0.284 & $1.21 \mathrm{E}-47$ & $9.22 \mathrm{E}-45$ \\
\hline 1462 & VCAN & 2.082 & 5.740 & $6.74 \mathrm{E}-47$ & $4.93 E-44$ \\
\hline 10631 & POSTN & 2.160 & 6.867 & $1.07 E-46$ & 7.52E-44 \\
\hline
\end{tabular}

and the JAK-STAT pathway were significantly enriched in high VDR group. The GSEA pathway analysis showed similar results: chemokine signaling, immune cell-related pathways, cell adhesion, cellular interactions and the JAK-STAT pathway, all of which are associated with carcinogenesis, were significantly enriched in the high VDR group compared to low VDR group (Supplementary Table 2). The 'chemokine signaling pathway' that was enriched in both DAVID and GSEA analysis harbors thyroid cancer related 'MAPK signaling pathway' composed with RAS-RAF-MEK-ERK1/2 cascade.

GO analysis conducted with EdgeR also showed increased immune-related biological processes, enrichment of cell membrane components and upregulation of receptor signaling activity in the high $V D R$ group. Top 10 enriched gene ontologies in high VDR group are listed in Supplementary Table 3.

\section{Discussion}

Although most thyroid carcinomas have a good prognosis, some types of cancer have intractable features and a significantly unfavorable prognosis. Current prognosis and treatment guidelines are based on clinicopathologic data. Recently, additional information using immunohistochemistry and molecular methods was introduced to improve the sensitivity and specificity of the diagnosis and to predict disease prognosis. Molecular markers such as BRAF, RAS, RET/PTC rearrangement, RAX8/PPAR $\gamma$ and galectin-3 may be useful for these purposes according to the American Thyroid Association guidelines (15).

The hallmark of thyroid cancer, besides aggressive behavior, is a loss of uptake and trapping of radioactive iodine, which means resistance to the best systemic therapy for thyroid cancer. The standard chemotherapy regimens approved for thyroid cancer have poor efficacy and relatively high toxicity compared to their benefit. Therefore, the discovery of alternative therapeutic targets for advanced differentiated thyroid cancer is important (16).

Vitamin D receptor is a member of the nuclear hormone receptor superfamily. It binds to DNA at vitamin D3 response elements upon ligand binding to alter the transcription of vitamin D3-responsive genes (17). Vitamin D3 appears to exert anticancer activity by decreasing proliferation, promoting re-differentiation, inhibiting angiogenesis and accentuating the effects of standard chemotherapy $(18,19,20,21)$.

This work is licensed under a Creative Commons Attribution-NonCommercial 4.0 International License. 
Clinical interest in the association of vitamin D levels with cancer, and in the potential of vitamin $\mathrm{D}$ receptor as a therapeutic target, has dramatically increased in recent years. A correlation between vitamin $\mathrm{D}$ and cancer prevention has been shown in breast, prostate and colorectal cancer (22). It rises to a consensus conference by the World Health Organization evaluating the evidence associated with vitamin D and cancer (23). Observational, preclinical and clinical studies strongly suggest that vitamin D3 deficiency increases the risk of developing multiple malignancies, whereas other studies do not support this hypothesis (24). However, several studies suggest that adequate vitamin D3 levels may provide protection against chronic diseases such as cancer and may improve cancer prognosis $(25,26,27)$. Expression of the VDR gene and 25-hydroxyvitamin D3 1- $\alpha$-hydroxylase, the rate-limiting enzyme in the production of active vitamin D3, has been found in several tissues and tumor types (28). Active vitamin D3 is important for regulating differentiation and cell growth in many different organs, and expression of 1a-hydroxylase/VDR is regarded as an important response against tumor progression.

A prior report by Izkhakov and coworkers showed that $V D R$ mRNA expression was higher in malignant thyroid tissues than that in normal thyroid tissues, which indicates a possible correlation between VDR gene expression and thyroid cancer prognosis (2); however, there were no clinicopathological differences between patients with low levels of gene expression and those with high levels of gene expression. Clinckspoor and coworkers reported that lower vitamin D3 metabolism was associated with the progression of thyroid cancer of follicular origin (29). Here, we found that overexpression of $V D R$ mRNA was correlated with aggressive PTC subtypes - classic PTC and TCVPTC, lateral neck node metastasis, advanced tumor (T4) and AJCC stage (IV) and worse recurrence-free survival. Our results also showed an association between high VDR mRNA and $B R A F^{\mathrm{V} 600 \mathrm{E}}$ mutant PTC, although did not gain statistical significance. Chemokine signaling pathway enrichment that harbors MAPK signaling cascade derived from two different pathway analyses also suggest that high $V D R$ expression may be associated with thyroid cancer progression by enhancing MAPK pathway. Overall, results show that overexpression of VDR mRNA is associated with poor prognostic factors in PTC, aggressive subtype, advanced T and AJCC stage, lateral neck node metastasis and worse recurrence-free survival.

One possible explanation for these results is impaired expression of vitamin D receptor on the cell membrane:
$V D R$ mRNA may be overexpressed in response to decreased vitamin $\mathrm{D}$ receptor protein expression in damaged cellular membranes. Another explanation may be genomic discordance between the expression levels of mRNA and the expression of protein. Guo and coworkers reported on the usefulness of mRNA to predict protein expression, but they described that the prediction of protein expression using mRNA was far from perfect (30). Because of limitations in our study design, the correlation between $V D R$ mRNA expression and vitamin D receptor protein expression could not be clearly assessed in this report. Further study in thyroid cancer is required.

In conclusion, we used public multigenomics data to demonstrate that elevated VDR mRNA levels are associated with aggressive PTC subtypes, worse prognostic factors and recurrence-free survival. Further experimental validation should be performed to prove the biologic influence of $V D R$ and circulating vitamin D.

\section{Supplementary data}

This is linked to the online version of the paper at http://dx.doi.org/10.1530/ EC-17-0001.

\section{Declaration of interest}

The authors declare that there is no conflict of interest that could be perceived as prejudicing the impartiality of the research reported.

\section{Funding}

This study was supported by the Research Grant Number CB-2011-03-01 of the Korean Foundation for Cancer Research.

\section{References}

1 Cong D, He M, Chen S, Liu X, Liu X \& Sun H. Expression profiles of pivotal microRNAs and targets in thyroid papillary carcinoma: an analysis of the Cancer Genome Atlas. Journal of OncoTargets and Therapy 20158 2271-2277. (doi:10.2147/OTT.S85753)

2 Izkhakov E, Somjen D, Sharon O, Knoll E, Aizic A, Fliss D M, Limor R \& Stern N. Vitamin D receptor expression is linked to potential markers of human thyroid papillary carcinoma. Journal of Steroid Biochemistry and Molecular Biology 2016159 26-30. (doi:10.1016/j. jsbmb.2016.02.016)

3 Giovannucci E. Vitamin D and cancer incidence in the Harvard cohorts. Annals of Epidemiology 200919 84-88. (doi:10.1016/j. annepidem.2007.12.002)

4 Buras RR, Schumaker LM, Davoodi F, Brenner RV, Shabahang M, Nauta RJ \& Evans SR. Vitamin D receptors in breast cancer cells. Breast Cancer Research and Treatment 199431 191-202. (doi:10.1007/ BF00666153)

5 Deeb KK, Trump DL \& Johnson CS. Vitamin D signalling pathways in cancer: potential for anticancer therapeutics. Nature Reviews Cancer 20077 684-700. (doi:10.1038/nrc2196)

6 Kostner K, Denzer N, Muller CS, Klein R, Tilgen W \& Reichrath J. The relevance of vitamin $\mathrm{D}$ receptor (VDR) gene polymorphisms http://www.endocrineconnections.org DOI: 10.1530/EC-17-0001
() 2017 The authors Published by Bioscientifica Ltd
This work is licensed under a Creative Commons Attribution-NonCommercial 4.0 International License. 
for cancer: a review of the literature. Anticancer Research 200929 3511-3536.

7 Krishnan AV, Trump DL, Johnson CS \& Feldman D. The role of vitamin D in cancer prevention and treatment. Rheumatic Disease Clinics of North America 201238 161-178. (doi:10.1016/j. rdc.2012.03.014)

8 Zinser GM, Suckow M \& Welsh J. Vitamin D receptor (VDR) ablation alters carcinogen-induced tumorigenesis in mammary gland, epidermis and lymphoid tissues. Journal of Steroid Biochemistry and Molecular Biology 200597 153-164. (doi:10.1016/j.jsbmb.2005.06.024)

9 Uitterlinden AG, Fang Y, Van Meurs JB, Pols HA \& Van Leeuwen JP. Genetics and biology of vitamin D receptor polymorphisms. Gene 2004338 143-156. (doi:10.1016/j.gene.2004.05.014)

10 Cancer Genome Atlas Research Network. Integrated genomic characterization of papillary thyroid carcinoma. Cell 2014159 676-690. (doi:10.1016/j.cell.2014.09.050)

11 Robinson MD, McCarthy DJ \& Smyth GK. edgeR: a Bioconductor package for differential expression analysis of digital gene expression data. Bioinformatics 201026 139-140. (doi:10.1093/bioinformatics/ btp616)

12 Huang da W, Sherman BT \& Lempicki R. A systematic and integrative analysis of large gene lists using DAVID bioinformatics resources. Nature Protocols 20094 44-57. (doi:10.1038/nprot.2008.211)

13 Huang da W, Sherman BT \& Lempicki RA. Bioinformatics enrichment tools: paths toward the comprehensive functional analysis of large gene lists. Nucleic Acids Research 200937 1-13. (doi:10.1093/nar/gkn923)

14 Subramanian A, Tamayo P, Mootha VK, Mukherjee S, Ebert BL, Gillette MA, Paulovich A, Pomeroy SL, Golub TR, Lander ES, et al. Gene set enrichment analysis: a knowledge-based approach for interpreting genome-wide expression profiles. PNAS 2005102 15545-15550. (doi:10.1073/pnas.0506580102)

15 Haugen BR, Alexander EK, Bible KC, Doherty GM, Mandel SJ, Nikiforov YE, Pacini F, Randolph GW, Sawka AM, Schlumberger M, et al. 2015 American thyroid association management guidelines for adult patients with thyroid nodules and differentiated thyroid cancer: the American thyroid association guidelines task force on thyroid nodules and differentiated thyroid cancer. Thyroid 201626 1-133. (doi:10.1089/thy.2015.0020)

16 Sherman SI. Advances in chemotherapy of differentiated epithelial and medullary thyroid cancers. Journal of Clinical Endocrinology and Metabolism 200994 1493-1499. (doi:10.1210/jc.2008-0923)

17 MacDonald PN, Baudino TA, Tokumaru H, Dowd DR \& Zhang C. Vitamin D receptor and nuclear receptor coactivators: crucial interactions in vitamin D-mediated transcription. Steroids 200166 171-176. (doi:10.1016/S0039-128X(00)00200-2)

18 Ali MM \& Vaidya V. Vitamin D and cancer. Journal of Cancer Research and Therapeutics 20073 225-230. (doi:10.4103/0973-1482.38998)

19 Ma Y, Yu WD, Hershberger PA, Flynn G, Kong RX, Trump DL \& Johnson CS. 1alpha,25-Dihydroxyvitamin D3 potentiates cisplatin antitumor activity by p73 induction in a squamous cell carcinoma model. Molecular Cancer Therapeutics 20087 3047-3055. (doi:10.1158/1535-7163.MCT-08-0243)

20 Wu FS, Zheng SS, Wu LJ, Teng LS, Ma ZM, Zhao WH \& Wu W. Calcitriol inhibits the growth of MHCC97 heptocellular cell lines by down-modulating c-met and ERK expressions. Liver International 2007 27 700-707. (doi:10.1111/j.1478-3231.2007.01487.x)

21 Zhang X, Jiang F, Li P, Li C, Ma Q, Nicosia SV \& Bai W. Growth suppression of ovarian cancer xenografts in nude mice by vitamin D analogue EB1089. Clinical Cancer Research 200511 323-328. (doi:10.1158/1078-0432.CCR-05-0400)

22 Song M, Wu K, Chan AT, Fuchs CS \& Giovannucci EL. Plasma 25-hydroxyvitamin D and risk of colorectal cancer after adjusting for inflammatory markers. Cancer Epidemiology Biomarkers and Prevention 201423 2175-2180. (doi:10.1158/1055-9965.EPI-140712)

23 Sharma V, Fretwell D, Crees Z, Kerege A \& Klopper JP. Thyroid cancer resistance to vitamin $D$ receptor activation is associated with 24-hydroxylase levels but not the ff FokI polymorphism. Thyroid 2010 20 1103-1111. (doi:10.1089/thy.2010.0096)

24 Feldman D, Krishnan AV, Swami S, Giovannucci E \& Feldman BJ. The role of vitamin D in reducing cancer risk and progression. Nature Reviews Cancer 201414 342-357. (doi:10.1038/nrc3691)

25 Colston KW, Berger U \& Coombes RC. Possible role for vitamin D in controlling breast cancer cell proliferation. Lancet 19891 188-191. (doi:10.1016/S0140-6736(89)91204-X)

26 Haussler MR, Whitfield GK, Haussler CA, Hsieh JC, Thompson PD, Selznick SH, Dominguez CE \& Jurutka PW. The nuclear vitamin D receptor: biological and molecular regulatory properties revealed. Journal of Bone and Mineral Research 199813 325-349. (doi:10.1359/ jbmr.1998.13.3.325)

27 Mawer EB, Walls J, Howell A, Davies M, Ratcliffe WA \& Bundred NJ. Serum 1,25-dihydroxyvitamin D may be related inversely to disease activity in breast cancer patients with bone metastases. Journal of Endocrinology and Metabolism 199782 118-122. (doi:10.1210/ jc.82.1.118)

28 Zehnder D, Bland R, Williams MC, McNinch RW, Howie AJ, Stewart PM \& Hewison M. Extrarenal expression of 25-hydroxyvitamin d(3)-1 alpha-hydroxylase. Journal of Endocrinology and Metabolism 200186 888-894. (doi:10.1210/jcem.86.2.7220)

29 Clinckspoor I, Hauben E, Verlinden L, Van den Bruel A, Vanwalleghem L, Vander Poorten V, Delaere P, Mathieu C, Verstuyf A $\&$ Decallonne B. Altered expression of key players in vitamin D metabolism and signaling in malignant and benign thyroid tumors. Journal of Histochemistry and Cytochemistry $201260502-511$. (doi:10.1369/0022155412447296)

30 Guo Y, Xiao P, Lei S, Deng F, Xiao GG, Liu Y, Chen X, Li L, Wu S, Chen $\mathrm{Y}$, et al. How is mRNA expression predictive for protein expression? A correlation study on human circulating monocytes. Acta Biochimica et Biophysica Sinica 200840 426-436. (doi:10.1111/ j.1745-7270.2008.00418.x)

Received in final form 2 January 2017

Accepted 21 February 2017

Accepted Preprint published online 21 February 2017 http://www.endocrineconnections.org DOI: 10.1530/EC-17-0001
(C) 2017 The authors Published by Bioscientifica Ltd

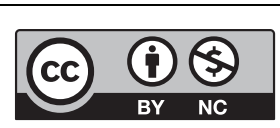

This work is licensed under a Creative Commons Attribution-NonCommercial 4.0 International License. 